\title{
Autom atic Priming Effects for New Associations in Lexical Decision and Perceptual Identification
}

\author{
Diane Pecher and Jeroen G. W. Raaijmakers \\ University of Amsterdam, Amsterdam, The Netherlands
}

\begin{abstract}
Information storage in semantic memory was investigated by looking at automatic priming effects for new associations in two experiments. In the study phase, word pairs were presented in a paired-associate learning task. Lexical decision and perceptual identification were used to examine priming effects during and after the study phase. There was automatic priming for new associations. The priming effect was greatly reduced when different semantic tasks were used at study and test compared to when identical tasks were used at study and test. The results show that new associations in semantic memory can be accessed automatically but are still context dependent. This suggests that rather than being abstract and static, retrieval from semantic memory interacts dynamically with the context.
\end{abstract}

When people process language, they make use of a large amount of information about words, such as their sound, their meaning, and the relations between them. Tulving (1972) referred to all this knowledge as semantic memory. Most research on semantic memory focuses on the representation of this knowledge, and on the processes that make use of this knowledge in order to produce speech or to read. Little is known, however, about how new knowledge is added to semantic memory. In the present paper we will address this issue by studying the storage of new associations in semantic memory.

In semantic memory tasks, such as lexical decision, associative priming is a general finding. The response to a word (e.g. bread) is faster and more accurate if the target word is presented in the context of an associated word, the prime (e.g. butter), than if it is presented in the context of an unrelated prime (e.g. chair). This associative priming effect was first obtained by Meyer and Schvaneveldt (1971) and has been replicated many times in both naming (Balota \& Lorch, 1986; Seidenberg, Waters, Sanders, \& Langer, 1984) and lexical decision (McNamara, 1992a; see Neely, 1991, for an overview). In the present study we investigated if an automatic priming effect can be found for new associations.

Requests for reprints should be sent to Diane Pecher, Department of Psychonomics, Roetersstraat 15, 1018 WB Amsterdam, The Netherlands. E-mail: pn_pecher@macmail.psy.uva.n1

The authors wish to thank Chris Schrijnemakers for the use of stimulus materials and software, and René Zeelenberg for useful suggestions. 
Priming for new associations has been studied in view of the distinction between episodic and semantic memory. According to Tulving (1972, 1983, 1984) episodic and semantic memory can be viewed as separate systems. Episodic memory consists of memories for specific events that are organized according to their temporal and spatial characteristics. Semantic memory consists of more abstract knowledge about words, such as their meaning and the relations among them. It comprises all of lexical memory. Episodic memory is used in tasks such as recognition and recall, where explicit reference is made to the study episode. For tasks such as lexical decision there is no reference to a study episode, and performance is dependent on information from semantic memory. Therefore, they can be considered semantic memory tasks. Dagenbach, Horst, and Carr (1990) argued that automatic priming in lexical decision is the result of associations in semantic memory. According to them, automatic priming will not be found if words are associated only in episodic memory. Thus, if priming is found for new associations, there is evidence that this new association is integrated into semantic memory. M cKoon and Ratcliff (1979, 1986), however, argued that if priming is found for new associations this is evidence against the distinction between episodic and semantic memory. According to them, if the two memory systems are separate it should be possible to access episodic and semantic information independently. Because lexical decision is a semantic memory task it should not be affected by episodic information. If there is priming for episodic associations this suggests that semantic and episodic information are stored in one memory system.

There is no independent way of differentiating between the view that episodic associations have become semantic or the view that episodic associations will be stored in the same system as semantic associations. In both cases there will be priming for new associations. However, both of the above explanations-the two-system model of memory and the single-system model of memory-would interpret automatic priming for new associations as evidence that these new associations are added to the same memory system as that in which old associations are represented. Such an effect shows that new information is somehow integrated into the existing semantic knowledge, which includes all lexical knowledge. Therefore, priming for new associations provides insights regarding the storage of new semantic information in memory.

Priming effects for old associations have been attributed to both automatic and controlled processes (De Groot, 1983; Neely, 1991; Posner \& Snyder, 1975). There are several models of automatic priming effects. The most common explanation is automatic spreading activation (Anderson, 1983; Collins \& Loftus, 1975). Alternative explanations are given by the compound cue theory (Ratcliff \& McKoon, 1988) or by distributed memory models (Masson, 1995). These three models offer explanations of automatic priming effects. Automatic priming occurs without the conscious attention of the subject and is fast acting. In addition to automatic processes, two additional processes that are more controlled have been postulated (De Groot, 1983; Neely, 1991; Posner \& Snyder, 1975). One such strategic process is expectancy generation, which assumes that subjects notice the associative relation between some of the prime-target pairs and generate expectations about the target after having read the prime. If the subsequent target matches the expectation, the response will be faster. Because some time is needed to generate an expectation this process will only be effective with a long stimulus-onset asynchrony (SOA) (Neely, 1977). In addition to expectancy generation another strategic 
process, called relatedness checking, is assumed to influence response times (Balota \& Lorch, 1986; De Groot, 1983; Pecher, Zeelenberg, \& Raaijmakers, 1998; Seidenberg et al., 1984). It is assumed that subjects make use of the correlation between relatedness and response. The subject searches for a relation between prime and target after the target is recognized. The existence of such a relation indicates that the target is a word (since nonwords cannot be related) and thus speeds the decision process. The absence of a relation results in a bias to make a nonword response and thus inhibits the word response. It is usually assumed that this process will on ly be used when subjects notice the presence of related word pairs (Shelton \& M artin, 1992).

The three explanations for automatic priming differ in many aspects (see, for example Masson, 1995; McKoon \& Ratcliff, 1992; McNamara, 1992a, 1992b, 1994a, 1994b; Ratcliff \& McKoon, 1994, 1995; Zeelenberg, Pecher, De Kok, \& Raaijmakers, 1998). However, they agree that automatic priming is caused by information in memory. According to all explanations, words can be related in memory, and it is this relation that causes the priming effect. For our purposes it is important to show that there is automatic priming for the new associations and that the effect cannot be explained by a strategy. Especially after extensive study, a strategy that makes use of episodic information becomes more likely. If new associations are similar to old associations there should be automatic priming for the new associations just as is found for old associations. Therefore, the experimental procedure that is used should minimize the influence of strategies that affect the priming effects.

Several studies have investigated priming effects for new associations. Some have failed to find priming for new associations (Carroll \& K irsner, 1982; Durgunoglu \& N eely, 1987; Smith, MacLeod, Bain, \& Hoppe, 1989), but others have obtained priming effects (Dagenbach et al., 1990; Den Heyer, 1986; Goshen-Gottstein \& Moscovitch, 1995; McKoon \& Ratcliff, 1979, 1986; Schrijnemakers \& Raaijmakers, 1997). However, interpretation of some of these results is complicated because different baselines have been used to measure the priming effect. Because the priming effect is the difference between the performance for new associations and performance for a control condition, it is important which control condition is used. Different control conditions that have been used include pairs with non-studied words as primes and studied words as targets, or pairs with neutral primes such as blank, or recombined pairs of primes and targets from different studied pairs. The priming effect for new associations should be measured relative to a recombined control condition. Otherwise, if the control condition has non-studied primes, or a repeatedly used neutral prime (blank), there is a confounding between prime familiarity and experimental condition. Smith et al. (1989) have shown that the familiarity of the prime can affect response times. Therefore, all words used in the experiments should receive the same amount of study so that different conditions are not confounded with different amounts of study. Den Heyer (1986) presented word pairs repeatedly in lexical decision and observed that the priming effect for repeated pairs depended on the time between the onset of the prime and the onset of the target (SOA). This dependency of SOA suggests that the effect is the result of an expectancy strategy (Neely, 1977). However, in the critical experiment his control condition was a neutral prime condition. This introduces a confound ing between the effect of forming a new association and the effect of prime repetition. A similar problem occurs with the 
experiments by Dagenbach et al. (1990) and Schrijnemakers and Raaijmakers (1997). In both these studies nonstudied primes were used in the control condition. Thus, an intact pair consisted of a studied target and a studied prime, whereas a recombined pair consisted of a studied target and a non-studied prime. Thus, in all these studies the amount of study for the primes was confounded with the experimental conditions. A better control condition is a recombined condition, in which words from studied pairs are recombined to form unrelated pairs, so that all words have received the same amount of study. Some studies that used an unrelated recombined baseline did not obtain an effect (Carroll and Kirsner, 1982; Smith et al., 1989) but others obtained priming for new associates (Goshen-Gottstein \& Moscovitch, 1995; McKoon \& Ratcliff, 1979, 1986). However, Goshen-Gottstein and Moscovitch found priming only when the presentation format of the prime-target pairs was identical at study and test. McKoon and Ratcliff presented very short lists (six pairs) for paired associate study, immediately followed by lexical decision. This may have induced strategic processes in the lexical decision task.

Hence, results do not unambiguously show that automatic priming can be obtained for new associations. In the present study we investigated whether automatic priming can be found with procedures that minimize the use of strategies, and with the correct recombined control condition. If automatic priming is found for new associations, this indicates that these associations are added to the system in which old associations are represented.

In addition, we investigated two issues that have hardly been addressed in previous research. The first issue is the interaction between the effect of study during the experiment and the pre-experimental relation between two words. When both old (e.g. butterbread) and new associations (e.g. chair-bread) are studied the effect is expected to be larger for new associations. This is because the old associations already have a strong relation in memory and will benefit less from additional study. To investigate this the old associations should receive the same amount of study as the new associations. Schrijnemakers and Raaijmakers (1997) investigated this in several experiments and obtained an interaction in one experiment. However, this finding should be interpreted with caution, because they used non-studied primes in the control condition. In the present study, priming effects for old and new associations are compared using a baseline of recombined studied word pairs.

A second issue is that semantic memory is usually assumed to be abstract and thus context independent (Tulving, 1984). Therefore, if new associations are added to semantic memory, the priming effect should transfer to tasks that were not used in the study phase of the experiment. For old associations there is priming in a variety of semantic memory tasks, and this should also be the case for new associations if these have been added to the same system. Goshen-Gottstein and Moscovitch (1995) found that priming for new associations was sensitive to the exact experimental procedure, and they argued that priming was dependent on the amount of overlap between study and test. Schrijnemakers and Raaijmakers (1997) did obtain transfer of priming from lexical decision in the study phase to perceptual identification in the test phase. The purpose of the first experiment reported in the present paper is to try to replicate Schrijnemakers and Raaijmakers' results, but this time using intralist primes only, so that the priming effects for related and unrelated word pairs can be compared directly. 


\section{EXPERIMENT 1}

In the present experiment, word pairs were repeatedly presented for study and for lexical decision. Two types of word pairs were presented-previously associated pairs and previously unrelated pairs. During this study phase, lexical decision times for these word pairs were compared to those for a neutral prime condition. After the study phase, some word pairs were recombined, and priming effects for new associations were investigated by comparing intact with recombined word pairs. In this test phase the word pairs were presented in lexical decision and in perceptual identification. Perceptual identification was included in order to investigate transfer of the priming effect for new associations to a task that was not used in the study phase.

\section{Method}

\section{Subjects}

Thirty-one students of the University of Amsterdam participated in the experiment. They recieved course credit for their participation.

\section{Stimulus Materials and Apparatus}

A master file was constructed with 128 associated word pairs. These word pairs were chosen from word association norms (De Groot, 1980; Lauteslager, Schaap, \& Schievels, 1986; Van Loon-Vervoorn \& Van Bekkum, 1991) so as to be strongly associated pre-experimentally. T he mean association frequency of these word pairs was $49.9 \%(S D=18.0) .{ }^{1}$ A second list was constructed with 32 pronounceable nonwords. The nonwords consisted of Finnish words and pseudowords derived from real Dutch words by changing some letters. All nonwords were pronounceable and orthographically legal.

For the practice trials a new set of 42 associates and a list of 14 nonwords were created. None of the words and nonwords in these sets appeared in the set of experimental word pairs. Of the associates, 14 were randomly recombined to form unrelated word pairs, 14 were used for the related condition, and the remaining 14 were used in the nonword condition. For the perceptual identification threshold task a list of 60 unrelated word pairs was created. None of the words from this list appeared in the other sets.

For the lexical decision task, presentation was controlled by an IBM PC. The words were presented on a standard monochrome display. For the perceptual identification task, a Hewlett Packard digital display module (model 1345A) was used. With this display presentation times could be varied in steps of $2 \mathrm{msec}$.

\section{Design}

The experiment consisted of two phases. During the study phase, word pairs were presented for lexical decision and paired associate learning. During the test phase, half of the word pairs were recombined. For each subject an experimental file was created by randomly selecting word pairs from the master file for each condition. For the word targets there were two conditions in the paired

\footnotetext{
${ }^{1}$ Association frequency refers to the percentage of subjects who gave the target as their first response to the prime in a free association task.
} 
associate learning task during the study phase: related and unrelated. For the lexical decision task there were three conditions during the study phase: related, unrelated, and neutral. For the lexical decision task there were five word target conditions during the test phase: intact-related, recombined-related, intact-unrelated, recombined-unrelated, and neutral. These conditions are displayed in Table 1 .

In the study phase the associated condition consisted of 16 word pairs from the master file. For the unrelated condition 48 word pairs were constructed by recombining primes and targets so as to form unrelated pairs. For the nonword condition 32 nonwords were paired to the remaining 32 word primes. No word appeared more than once on the list. These pairs were used during the study phase of the experiment.

In the test phase four new conditions of 16 word pairs each were created using the same words. These conditions were: intact-associated, recombined-associated, intact-unrelated, and recombined-unrelated. In the intact-associated and the intact-unrelated conditions the word pairs were the same as in the study phase. The recombined-associated condition was created by recombining 16 primes with their associatively related targets. The recombined-unrelated condition was created by recombining 16 primes to unrelated targets. Note that all primes and targets were studied the same number of times.

In the lexical decision task there was one additional neutral condition in both the study phase and the test phase. In this condition the prime consisted of the word blanco (blank). For half of the word trials and half of the nonword trials the word prime was replaced by the word blanco. Thus both word primes and neutral primes were equally likely to be followed by a word or a nonword target.

\section{Procedure}

Study Phase. Prime-target pairs were presented 11 times, over three sessions. Each session was on a different day, with an interval of 24-48 hours between consecutive sessions. On the first and second session all pairs were presented four times, and on the third session all pairs were presented three times. This was done in presentation blocks; all word pairs were presented once in each block.

During the study phase of the experiment the subjects performed two tasks-lexical decision and paired associate learning. A trial consisted of the following sequence: a warning signal $(*)$ for $1000 \mathrm{msec}$, the prime for $100 \mathrm{msec}$, a blank screen for $40 \mathrm{msec}$, and then the target, which was

TABLE 1

Conditions in Experiment 1 with Examples

\begin{tabular}{llll}
\hline & \multicolumn{2}{c}{ Study } & Phase \\
\cline { 2 - 3 } Condition & Study Task & Lexical Decision & \multirow{2}{*}{ Test Phase } \\
\hline Intact-Associated & finger-thumb & finger-thumb & finger-thumb \\
Recombined-Associated & bread-cow & bread-cow & milk-cow \\
Intact-Unrelated & silver-crime & silver-crime & silver-crime \\
Recombined-Unrelated & milk-harbor & milk-harbor & bread-harbor \\
Neutral & car-mother & blank-mother & blank-mother \\
& wet-dry & blank-dry & blank-dry \\
\hline
\end{tabular}

Note: The intact/ recombined distinction does not play a role in the study phase because the pairs are only recombined in the test phase. 
presented until the subject had made a response by pressing either the "?/" key (word) or the " $Z$ " key (nonword) of the computer keyboard. The warning signal, prime, and target were all displayed at the same location in the centre of the PC screen. For half of the word targets and half of the nonword targets the prime was the word blanco [blank] to form the neutral baseline condition. Feedback was given about the speed and accuracy of the response.

If the target was a word, the prime-target pair was displayed again, and the subjects were instructed to study the word pair. If the target had been preceded by the blanco prime, the prime was replaced by a word prime. During the first presentation block the pair was presented for $5 \mathrm{sec}$; during the following presentation blocks this was reduced to $3 \mathrm{sec}$. All word pairs were presented the same number of times so that repetition effects were equal for all items. If the target was a nonword, the next trial started immediately after the feedback on speed and accuracy of the response.

On each day the session started with 42 practice trials. On the first and second day the experimental lexical decision trials were given in four blocks of 96 prime-target pairs each. On the third day there were three blocks. For each presentation block the order of the prime-target pairs was randomized. After each presentation block there was a short break. At the end of each session the subjects received a cued recall test for the word targets. The first word (the prime) of a word pair was presented on the screen, and the subject was asked to write down the second word (the target). After $7 \mathrm{sec}$ the next word appeared on the screen. The order of the primes was randomized.

Test Phase. Immediately after the last session of the study phase (i.e. on the third day) the test phase started. In the test phase half of the studied word pairs were recombined so that the list consisted of intact and recombined pairs. During the test phase the subjects performed two tasks-lexical decision and perceptual identification. Half of the subjects did the lexical decision task first; the other half did the perceptual identification task first. The lexical decision task was the same as that used during the study phase, except that this time the word pairs were not displayed again for study after the subject had made a response. So the next trial started immediately after the subject made a response and feedback was given.

The perceptual identification task was based on the four-field procedure of Evett and Humphreys (1981). A trial consisted of the following sequence: a fixation point $(700 \mathrm{msec})$, a forward pattern mask (700 msec), a prime, a target, and a backward pattern mask (700 msec). The presentation time for the prime was always equal to the presentation time of the target and was determined individually for each subject.

Before the experimental task started, the subjects performed 10 practice trials. A prime-target pair was presented in the manner described above, and subjects had to report which words they had seen. Subjects were encouraged to respond even if they were not sure about the identity of the target. After the subject made a response, feedback was given by presenting the same word pair again without masks. After the practice trials each subject received a series of 60 trials in order to determine the presentation time for the primes and targets. During this procedure, unrelated primes and targets were presented for six different durations (10 trials for each duration): 26, 32, 38, 44, 50, and $56 \mathrm{msec}$. These durations were used in random order. A logistic function was used to fit the psychometric function for each individual subject. The parameters of the logistic function were used to estimate the threshold at which there would be $40 \%$ correct identification. The presentation times determined this way varied between $30 \mathrm{msec}$ and $52 \mathrm{msec}$ with a mean of $40.32(S D=5.54)$.

The perceptual identification task consisted of all 64 word pairs, in the same combination as in the lexical decision task during the test phase. In the neutral condition the word blanco was replaced by the appropriate word prime. The nonwords were not presented in the identification task. 


\section{Results}

\section{Study Phase}

Only reaction times for correct responses that fell with in the range 150-900 msec were used for the analyses. This resulted in the removal of $1.1 \%$ of the data. The mean lexical decision times for words are presented in Figure 1. Lexical decisions become faster with repetition of the target and more so in the unrelated and associative condition than in the neutral condition. An $11 \times 3$ ANOVA (Presentation $\times$ Prime Type) was performed on the reaction times for words. The two main effects (of presentation, $F(10,300)=31.32$, $M S e=2389.3$, and of prime-type, $F(2,60)=53.45, M S e=2321.5)$ were significant, as was the interaction, $F(20,600)=8.72, M S e=433.0$, all $p \mathrm{~s}<.001$. To test the expected interaction between study status and pre-experimental relation, another $11 \times 2$ ANOVA was performed on the data for the associated and unrelated word pairs only. Without the data from the neutral condition there was no interaction effect. Hence, the interaction obtained in the first analysis is due to the neutral condition, where the speed-up was slower than that in the other two conditions. At the end of every session, cued recall data

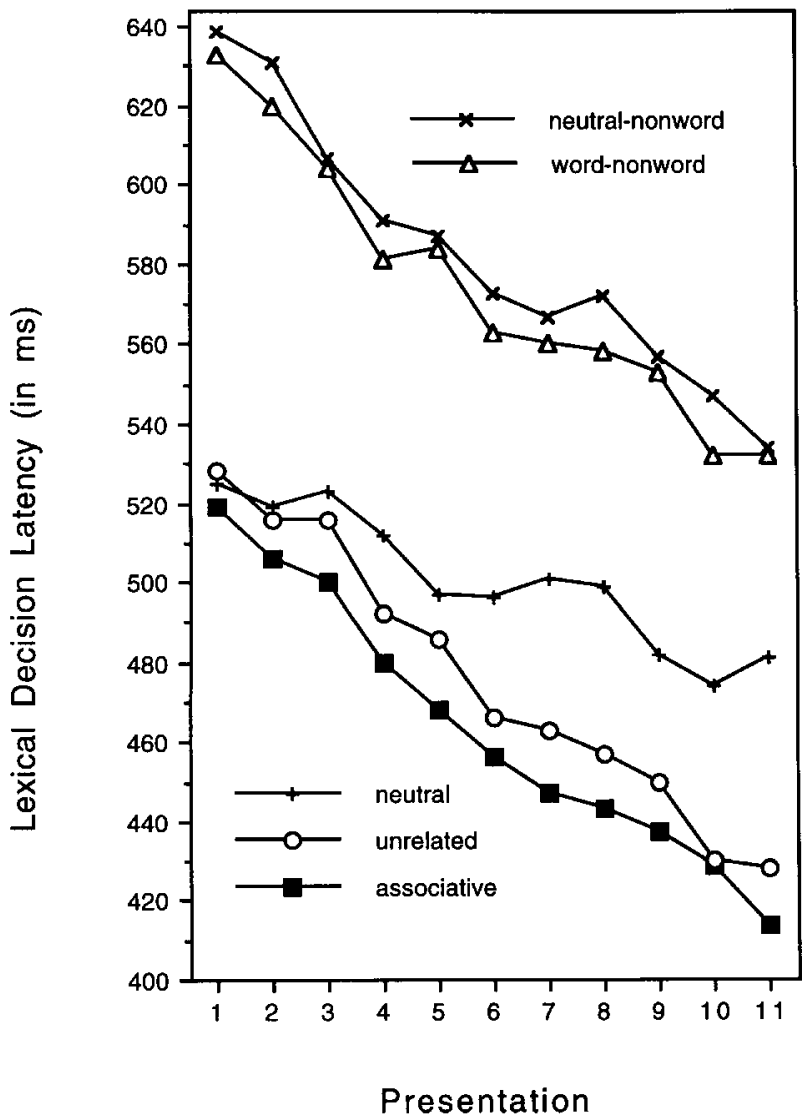

FIG. 1. Mean lexical decision latency (in $\mathrm{msec}$ ) in the study phase of Experiment 1 . 
were collected. These data are shown in Table 2. The results show that the word pairs were learned very well. These data are not analysed further because no hypothesis was made concerning the cued recall test.

\section{Test Phase}

Lexical Decision. Table 3, first column, shows the mean reaction times for the five conditions. There was an effect of study for the previously unrelated pairs, but not for the previously related pairs. This was confirmed by a 2 (intact vs. recombined) $\times 2$ (associated vs. unrelated) ANOVA. There was a marginally significant main effect for study status (intact vs. recombined word pairs), $F(1,30)=3.45, p=.07, M S e=811.5$. There was a marginal main effect for relatedness, $F(1,30)=2.97, p=.10, M S e=477.5$. The interaction effect between study status and relatedness was significant, $F(1,30)=5.25$, $p<.05, M S e=608.0$. Simple effects showed that this interaction was due to a significant effect of study for the previously unrelated word pairs, $F(1,30)=7.77$, $M S e=769.8, p<.01$, whereas there was no significant effect of study for the previously associated word pairs, $F<1$. A separate test showed that there was no significant

TABLE 2

Mean Percentage of Targets

Recalled in the Cued Recall Test

of Experiment 1

\begin{tabular}{lcc}
\hline Session & Associated & Unrelated \\
\hline 1 & 97 & 81 \\
2 & 99 & 96 \\
3 & 100 & 97 \\
\hline
\end{tabular}

TABLE 3

Mean Lexical Decision Latency ( $\mathrm{msec}$ ) and Mean Proportion Correct for Perceptual Identification During the Test Phase of Experiment 1

\begin{tabular}{|c|c|c|c|c|c|}
\hline \multirow[b]{3}{*}{ Condition } & & \multicolumn{4}{|c|}{ Task } \\
\hline & & \multicolumn{2}{|c|}{$L D$} & \multicolumn{2}{|c|}{$P I$} \\
\hline & & M & $S E$ & $M$ & $S E$ \\
\hline \multirow[t]{2}{*}{ Associated } & Intact & 419 & 9.0 & .70 & .025 \\
\hline & Recombined & 419 & 8.9 & .65 & .028 \\
\hline \multirow[t]{2}{*}{ Unrelated } & Intact & 416 & 8.2 & .62 & .027 \\
\hline & Recombined & 436 & 10.3 & .59 & .031 \\
\hline Neutral & & 433 & 7.1 & - & \\
\hline
\end{tabular}

$\mathrm{LD}=$ lexical decision; $\mathrm{PI}=$ perceptual identification. 
difference between the recombined-unrelated and neutral condition, $F<1$. Thus, both old and new associations are facilitated compared to the recombined-unrelated word pairs. The priming effect for intact word pairs is larger for previously unrelated than for previously related word pairs. In fact, for previously associated word pairs there is no significant effect of stuy.

Perceptual Identification. Table 3, second column, shows the proportion of correctly identified targets for the four conditions. The proportion of identified targets was higher (.07) for the associated word pairs than for the unrelated word pairs. This was confirmed by a $2 \times 2$ ANOVA, which showed a main effect of association, $F(1,30)=5.97, p<.05$, $M S e=0.014$. The difference between the intact and recombined word pairs was smaller (.04) and not statistically significant, $F(1,30)=1.43, p>.10, M S e=0.014$. There was no evidence for an interaction, $F(1,30)=0.11, p>.10, M S e=0.011$.

\section{Discussion}

The results from this experiment show that there is a priming effect for new associations. During the study phase, lexical decision times for targets that were preceded by studied primes decreased at a faster rate than those for targets that were preceded by a neutral prime. Associations were learned between prime and target, and those associations resulted in faster lexical decisions to the target. These results replicate the priming effect that was obtained by Schrijnemakers and Raaijmakers (1997). The size of the priming effect for new associations in our results, $20 \mathrm{msec}$, is comparable to the $23-\mathrm{msec}$ priming effect that was obtained by Dagenbach et al. (1990, Experiment 4). They investigated priming for unrelated word pairs after extensive study. In their study this $23-\mathrm{msec}$ difference was not significant, possibly because it was based on fewer observations (12 subjects) than that in our study (31 subjects). Therefore, if we take together our results and those of Dagenbach et al. and Schrijnemakers and Raaijmakers, it seems that priming effects for new associations can be obtained, although the effect is not very large. In our experiment the control condition consisted of recombined word pairs, of which both words had been studied in the study phase. This is a better control condition than one in which the primes were new, nonstudied words. That a priming effect was obtained in our experiment indicates that the effect that both Dagenbach et al. and Schrijnemakers and Raaijmakers obtained was not entirely attributable to the extralist primes they used in their control condition.

Unlike Schrijnemakers and Raaijmakers we did not observe an interaction between relatedness and study status during the study phase. During the test phase, however, we did observe a significant interaction between relatedness and study status in lexical decision. There was an effect of study for unrelated pairs but not for related pairs. Thus, we have some indication that the new associations have indeed become functionally similar to old associations. However, the priming effect for new associations did not seem to transfer to the perceptual identification task. The small difference between the intact and recombined condition was not significant. The absence of transfer would argue against the view that the new associations had become functionally similar to old associations, because if they had, we should have obtained priming in other semantic memory tasks. 
A second explanation of the priming effect for intact word pairs relative to the neutral condition in the study phase is that subjects learned prime-response associations. If subjects noticed that all studied primes were always followed by word targets, seeing a studied prime was enough to produce a yes response. This would speed up the lexical decisions for word-word pairs considerably compared to those for the neutral condition. In the neutral condition such a prime-response association was not possible, because the neutral prime could be followed by both word and nonword targets. However, during the study phase the difference between the unrelated and related word pairs remained constant. If subjects had responded to the primes instead of to the targets, one would expect the associative priming effect to decrease with repetitions. Moreover, during the test phase there was a difference between the recombined unrelated condition and the three other conditions. If subjects had responded to the prime, there should have been no difference between these conditions, because all primes were studied.

A third explanation for the priming effect we obtained concerns the strategies that have often been associated with priming effects in lexical decision. In addition to automatic priming, two additional strategies have been proposed to explain priming effects. These strategies are expectancy generation and relatedness checking. The expectancy generation strategy should not have played a role in the present experiment, because the prime-target SOA was very short. For subjects to generate expectancies about the target a longer SOA than the $140 \mathrm{msec}$ in our procedure is needed (Neely, 1977). However, relatedness checking may still play a role at short SOAs. According to th is explanation, after the target is recognized the subject searches for a relation between prime and target. If prime and target are related there is a bias to respond word and this speeds up the decision process. If there is no relation between the prime and target there will be a bias to respond nonword and this results in inhibition for unrelated word pairs. In Experiment 1 , there were two types of relations that played a role-old and new associations. In the test phase, responses were slower to word pairs that had neither type of relation than to the other three types of word pairs. It is possible that an inhibitory effect resulted from seeing a word pair that had neither a meaningful nor a learned relation, especially because in this experiment a lot of emphasis was put on learning the word pairs. However, the relatedness-checking strategy predicts inhibition for unrelated word pairs compared to a neutral condition (De Groot, Thomassen, \& Hudson, 1986). But in the test phase there was no difference between lexical decision times to unrelated recombined pairs and those to the neutral pairs. Thus, the results suggest that relatedness checking also does not explain the data pattern.

Therefore, our data suggest that the results are not affected by strategies. However, because the lexical decision task is a binary decision task it is sensitive to strategies. The purpose of Experiment 2 was to investigate priming for new associations in a task that is less sensitive to strategies, such as the perceptual identification task that we used in the test phase. This task is less sensitive to strategies because a unique response has to be generated on each trial, and because the prime is masked. Studies have shown that an associative priming effect is obtained with this task (Evett \& Humphreys, 1981). In the next experiment we will therefore use perceptual identification as the primary task to investigate priming for new associations. Although lexical decision and perceptual identification are different tasks, both tasks measure activation of lexical information, and both 
tasks show priming for old associations. If new associations have been added to semantic memory, there should be priming in both tasks.

The priming effect for new associations we have obtained thus far is not very large. For new associations to be created, mere co-occurrence of the two words might not have a strong effect. Possibly two words have to be related in some meaningful way before they can become strongly associated in semantic memory. According to Shelton and Martin (1992) both co-occurence and semantic relation are necessary to produce priming. They showed that if strategic and post-lexical processes are prevented in a lexical decision task, no priming is found for word pairs that have a semantic relation but not an associative one. Although there is some disagreement on this issue (see our discussion of Experiment 2) for the present experiment it is important that we have selected pairs for which there is no priming but that have some semantic relation. If these word pairs would be studied they might become associated more easily than word pairs that have no obvious semantic relation. This is suggested by the Dagenbach et al. (1990) study. They presented word pairs in a very long study phase, spread out over 5 weeks. In one experiment the subjects learned the definition of new vocabulary words (e.g. drupe) and subsequently learned associations between the new words and familiar synonyms (e.g. drupe-cherry). After the study phase the new words were presented as primes and the familiar synonyms as targets. In this experiment there was priming for these new associations. In another experiment new associations between two unrelated familiar words were studied, and a small $(23 \mathrm{msec})$ priming effect was obtained, but this was not reliable. Dagenbach et al. concluded that it is easier to create a link with a new word than it is to create a link between two already existing but unrelated words. However, their results may indicate that it is easier to form a new association between two words if they have a semantic relation than if they are semantically unrelated. If we find a larger priming effect for semantically related word pairs than for unrelated word pairs this would give an alternative explanation for Dagenbach et al.'s results.

In the next experiment we made three important changes with regard to Experiment 1. These changes involved the priming task that was used during the study phase, the type of word pairs that were used, and the paired associate study tasks. Instead of the lexical decision task, the perceptual identification task was used during the study phase of the experiment. The perceptual identification task is less sensitive to response biases or relatedness-checking processes for two reasons. First, instead of making a binary decision, the subject has to produce the target; therefore the strategies that are associated with binary decision tasks cannot play a role. Second, the prime is masked, which minimizes the influence of strategies. In our next experiment, the lexical decision task was used in the test phase only, and the procedure was adjusted in such a way that the primes were masked. When primes are masked subjects are unable to report the prime and thus a relatedness-checking strategy is prevented, but there is still an automatic associative priming effect (De Groot, 1983; Neely, 1991). We investigated if we would still find priming for new associates with a procedure that minimizes the use of strategies.

In addition to the associated and the unrelated word pairs a set of word pairs with semantic but not associative relations was presented for study. These word pairs do not have an association according to free association nor $\mathrm{ms}$, but can be considered semantically related because they are exemplars of the same category. If semantic relatedness is an 
important factor in the development of new associations, these word pairs should show evidence of becoming associated more easily than the unrelated word pairs.

Finally, we changed the type of study tasks in such a way that they would result in stronger associations and would be less similar to the priming task. In Experiment 1 the subjects were simply instructed to study the word pairs for later cued recall, and th is study task was intermixed with lexical decision trials. In Experiment 2 additional instructions were given to promote meaningful processing of relations between the two words of a pair, such as their similarity. This should facilitate the creation of new associations. The study tasks were separated from the perceptual identification trials and presented on a different screen. This might make the new associations less sensitive to context.

\section{EXPERIMENT 2}

\section{Method}

\section{Subjects}

Forty-eight students of the University of Amsterdam participated in the experiment. They received course credit for the participation.

\section{Stimuli}

From word association norms 60 word pairs were chosen with a mean association frequency of $56.7 \%$ ( $S D$ 17.5). For every target a second prime was chosen that was from the same category according to category norms (Hudson, 1982) but not associated to the target according to association norms. These were the semantically related word pairs. For every target there was an associatively related prime and a semantically but not associatively related prime. In the unrelated condition primes and targets were recombined to form unrelated word pairs. Half of the unrelated pairs were formed from the semantic-only pairs and half from the associated pairs. Thus, both associated word pairs and semantic word pairs had their own unrelated control condition. Different lists were created to ensure counterbalancing. Targets were distributed over lists in such a way that for each condition the mean word frequency of the targets was about the same. With in a set all targets and primes were used only once. Each subject was presented with the same set throughout the experiment. The word and nonword stimuli used for practice trials, for the perceptual identification threshold-setting task, and for the word-nonword trials in the lexical decision task were selected from a different set. The nonwords were created by changing one letter of a real word in such a way that the letter string was still pronounceable.

\section{Procedure}

The experiment consisted of four different types of task: a perceptual identification task, a pairedassociate study task, a cued recall task, and a lexcial decision task. The experiment was distributed over two sessions, with a break of one week between the first and the second session.

The perceptual identification task was the same as the one used in Experiment 1. In the pairedassociate study task all word pairs were presented one by one on the computer screen of a Macintosh LC II for $8 \mathrm{sec}$ each. The subjects were instructed to study the pairs for later cued recall. This task was given four times during the entire experiment, each time with different instructions. These instructions were: (a) generate a sentence that includes the two words of the pair, (b) name a similarity 
between the two words, (c) name a difference between the two words, and (d) name a profession that has some relation to both words.

Each of the four study tasks was followed by a cued recall test for all 60 word pairs. The prime was presented on the screen and the subject was asked to respond by naming the target. After a response the correct target was displayed on the screen. The experimenter recorded whether the response was correct or not by pressing the appropriate button on the computer keyboard. This also initiated the next trial. At the end of the cued recall test, feedback was given on the number of correct responses. Because the correct target was always displayed this task can also be considered as an additional study task.

The lexical decision task was given in the test phase of the experiment. The task consisted of 60 word-word trials and 60 word-nonword trials. Subjects were asked to decide as quickly as possible whether a presented letter string represented an existing Dutch word. The primes were masked, and responses were made to the target only. Each trial consisted of a forward mask ( $480 \mathrm{msec})$, a blank screen $(20 \mathrm{msec})$, the prime $(40 \mathrm{msec})$, a blank screen $(20 \mathrm{msec})$ and the target. This procedure was also used by De Groot (1983). The target remained visible until the subject made a response by pressing one of two buttons (one for word and one for nonword). After the subject's response, feedback was given on accuracy and speed of the response. Then the next trial started. Before the critical lexical decision task a series of 40 practice trials (20 word and 20 nonword targets) was given.

Study Phase. The study phase of the experiment consisted of two parts, separated by a week. The first part started with the practice and threshold trials for the perceptual identification task, followed by the 60 critical trials. After the perceptual identification task the subjects were given two sequences of the paired-associate task and the cued recall test. After that there was a second perceptual identification task with the same word pairs. For the perceptual identification task the subjects were instructed not to use their memory for the word pairs but to report only words they thought they had seen.

One week after the first session the subjects returned. This second session started with perceptual identification of the 60 word pairs. Presentation times for prime and target were lowered to prevent ceiling effects. The new presentation time was determined by the equation $Y=(2 X+14) / 3$, where $Y$ is the new presentation time and $X$ is the old one. ${ }^{2}$

After the perceptual identification task there were again two sequences of paired-associate study and cued recall for the 60 word pairs. This was followed by perceptual identification. At this stage of the experiment the subjects had seen the word pairs 12 times: 4 times in perceptual identification, 4 times in the paired-associate study task, and 4 times in the cued recall task. These tasks together constituted the study phase of the experiment.

Test Phase. The test phase consisted of the perceptual identification task and the lexical decision task. Half of the word pairs were recombined to form new pairs. The resulting conditions were: intact-associatively related, recombined-associatively related, intact-semantically related, recombined-semantically related, intact-unrelated, and recombined-unrelated. All primes and targets came from the studied list. There were 10 word pairs in each condition. These word pairs were used in two tasks- perceptual identification and lexical decision.

\footnotetext{
${ }^{2}$ This equation was determined by setting the new thresholds for the lowest and the highest old thresholds and drawing a straight line between these points. For the lowest threshold, which was $26 \mathrm{msec}$, the new threshold was $22 \mathrm{msec}$. For the highest threshold, which was $50 \mathrm{msec}$, the new threshold was $38 \mathrm{msec}$. These new thresholds were chosen in such a way that the decrease was larger for higher than for lower thresholds.
} 


\section{Results}

\section{Study Phase}

The results of the study phase are shown in Table 4. In the first part of the study phase the subjects performed two perceptual identification tasks, one before studying the word pairs and one after studying the word pairs. A 2 (presentation) $\times 2$ (associative vs. semantic) $\times 2$ (relatedness) ANOVA showed that there was a main effect of presentation: The subjects identified more targets on the second presentation than on the first presentation, $F(1,47)=323.4, p<.001, M S e=0.020$. There was a significant main effect of relatedness, $F(1,47)=7.71, p<.01, M S e=0.021$. However, simple effects showed a relatedness effect for the associated word pairs, $F(1,47)=7.95, p<.01, M S e=0.021$, but not for the semantically related word pairs, $F(1,47)=1.30, p>.10, M S e=0.018$. The only other effect that reached significance was the three-way interaction, $F(1,47)=$ $4.99, p<.05, M S e=0.014$. The unrelated and semantically related word pairs benefited more from being studied than the associatively related word pairs.

In the second part of the study phase, which was held one week after the first part, the subjects again performed two perceptual identification tasks, one before studying the word pairs and one after studying the word pairs. A 2 (presentation) $\times 2$ (associative vs. semantic) $\times 2$ (relatedness) ANOVA showed that there was a main effect of presentation: The subjects identified more targets on the second presentation than on the first presentation, $F(1,47)=81.2, p<.001, M S e=0.024$. There was a marginally significant interaction between type of relation and relatedness, $F(1,47)=3.36, p=.07, M S e=$ 0.016. Simple effects showed that a significant priming effect was obtained for the associatively related word pairs, $F(1,47)=4.06, p=.05, M S e=0.016$, but not for the semantically related word pairs, $F<1$. None of the other effects reached significance.

Table 5 shows the percentages of recalled targets. The main purpose of the cued recall test was to serve as a type of study task. No analyses were performed on the data.

TABLE 4

Mean Proportion Correct for Perceptual Identification During the Study Phase of Experiment 2

\begin{tabular}{|c|c|c|c|c|c|c|}
\hline \multirow{3}{*}{$\frac{\text { Part }}{1}$} & \multirow{2}{*}{\multicolumn{2}{|c|}{ Presentation }} & \multicolumn{2}{|c|}{ Associative } & \multicolumn{2}{|c|}{ Semantic only } \\
\hline & & & \multirow{2}{*}{$\frac{M}{0.40}$} & \multirow{2}{*}{$\frac{S E}{0.024}$} & \multirow{2}{*}{$\frac{M}{0.36}$} & \multirow{2}{*}{$\frac{S E}{0.021}$} \\
\hline & 1 & Related & & & & \\
\hline & & Unrelated & 0.31 & 0.020 & 0.36 & 0.020 \\
\hline & 2 & Related & 0.62 & 0.027 & 0.64 & 0.027 \\
\hline & & Unrelated & 0.59 & 0.025 & 0.60 & 0.023 \\
\hline \multirow[t]{4}{*}{2} & 1 & Related & 0.31 & 0.022 & 0.31 & 0.023 \\
\hline & & Unrelated & 0.28 & 0.018 & 0.29 & 0.019 \\
\hline & 2 & Related & 0.46 & 0.026 & 0.42 & 0.024 \\
\hline & & Unrelated & 0.42 & 0.021 & 0.46 & 0.023 \\
\hline
\end{tabular}




\section{Test Phase}

After the study phase of the experiment there was a test phase. During the test phase the subjects performed two tasks: perceptual identification and lexical decision. There were two independent variables: study status (intact vs. recombined) and prime-target relation (associated, semantic, and unrelated).

The perceptual identification data are shown in Table 6. In the perceptual identification task there was a main effect of study status, $F(1,47)=7.07, p<.05, M S e=0.025$. There was no main effect of prime-target relation and no interaction effect, $F \mathrm{~s}<1$. Thus, in the perceptual identification task we observed priming for new associations. This priming effect was not different for the different types of prime-target relations.

The results for the lexical decision task are also shown in Table 6. The difference between intact and recombined word pairs was not significant, $F(1,47)=3.25, p=.08$, $M S e=822.2$. There was a main effect of relation, $F(2,94)=8.61, p<.001, M S e=752.8$. Responses were faster to associatively or semantically related word pairs than to unrelated word pairs, $F(1,47)=16.64, p<.001, M S e=644.4$, and, $F(1,47)=9.90, p<.01, M S e$ $=869.0$, respectively. There was no interaction effect, $F<1$. An unexpected finding was that responses were faster to semantically related than to unrelated word pairs. This effect

\section{TABLE 5}

Mean Percentage of Targets Recalled in the Cued Recall Test During the Study Phase of Experiment 2

\begin{tabular}{lcccc}
\hline Session & & Associative & Semantic Only & Unrelated \\
\hline 1 & Test 1 & 95 & 76 & 54 \\
& Test 2 & 99 & 94 & 78 \\
2 & Test 1 & 99 & 95 & 78 \\
& Test 2 & 100 & 99 & 89 \\
\hline
\end{tabular}

TABLE 6

Mean Lexical Decision Latency (msec) and Mean Proportion Correct for Perceptual Identification During the Test Phase of Experiment 2

\begin{tabular}{lllllll}
\hline & & \multicolumn{4}{c}{ Task } \\
\cline { 3 - 6 } & & \multicolumn{2}{c}{$P I$} & & \multicolumn{2}{c}{$L D$} \\
\cline { 3 - 4 } \cline { 5 - 7 } Condition & & $M$ & $S E$ & & $M$ & $S E$ \\
\hline \multirow{2}{*}{ Associative } & Intact & .48 & .026 & 515 & 7.5 \\
& Recombined & .44 & .025 & 518 & 7.3 \\
Semantic & Intact & .51 & .030 & 516 & 7.3 \\
& Recombined & .46 & .026 & 520 & 7.3 \\
Unrelated & Intact & .50 & .028 & 526 & 7.2 \\
& Recombined & .44 & .025 & 537 & 8.2 \\
\hline
\end{tabular}

$\mathrm{LD}=$ lexical decision; PI $=$ perceptual identification. 
was significant for the recombined pairs, $F(1,47)=8.86, p<.01, M S e=784.9$, and marginally significant for the intact pairs, $F(1,47)=3.25, p<.08, M S e=702.1$.

\section{Discussion}

The results clearly show that there is priming for new associations. They also show that this effect is not different for semantically related than for unrelated word pairs. All types of intact word pairs were primed compared to the recombined word pairs. Thus, we have obtained priming for new associations in the perceptual identification task, which is not sensitive to the kind of strategies that can play a role in lexical decision.

An unexpected finding in the lexical decision task in the test phase was that responses were faster to the recombined semantically related word pairs than to the recombined unrelated word pairs. Thus, we obtained semantic priming for these pairs. Before the study phase there was no priming effect for the semantically related word pairs in the perceptual identification task. In a pilot study using the same lexical decision procedure and the same stimuli as in Experiment 2, no priming was obtained for the semantically related word pairs, whereas there was significant priming for the associatively related word pairs. ${ }^{3}$ Thus, it is surprising that priming was obtained for the recombined semantic pairs after the study phase.

Other studies have also investigated priming for semantically but not associatively related word pairs. A number of studies have found priming effects for semantic-only word pairs (Fischler, 1977; L und, Burgess, \& Atchley, 1995; McRae, \& Boisvert, 1998; McRae, De Sa, \& Seidenberg, 1997; Seidenberg et al., 1984), but other studies have put such results into question (Lupker, 1984; Shelton \& Martin, 1992; Williams, 1996). According to Shelton and Martin (1992) priming effects for semantic-only word pairs are the result of strategies. They showed that in a single presentation procedure with a low relatedness proportion no priming is obtained for semantic-only word pairs. They argue that this shows that there is no automatic priming for semantic-only word pairs. In our experiments we have used prime-masking procedures to prevent the use of strategies. In perceptual identification there was no priming effect for the semantic-only pairs before the study tasks, but in lexical decision, after the word pairs were studied, there was priming for both intact and recombined semantic-only pairs. A possibility is that the context of the experiment played a role. Dagenbach, Carr, and Wilhelmsen (1989) showed that priming effects in lexical decision with a masked prime procedure are affected by the type of judgment (semantic or identity) that was made in a threshold-setting task just before the lexical decision task. For subjects that made identity judgments in the threshold-setting task priming was found when primes were presented below threshold. However, for subjects that made semantic similarity judgments in the threshold setting task inhibition was found for related pairs. It is possible that the perceptual identification task during the study phase of our experiments had some similar effect. Another related

\footnotetext{
${ }^{3}$ Nine subjects performed a lexical decision task with masked primes. The procedure of the lexical decision task and stimulus materials were the same as those in Experiment 2. Mean reaction times were $520 \mathrm{msec}$ for the associatively related word pairs, $548 \mathrm{msec}$ for the semantically related word pairs, and $533 \mathrm{msec}$ for the unrelated word pairs. A one way ANOVA showed an effect of prime type, $F(2,16)=6.515, p<.01, M S e=266.0$.
} 
finding by McKoon and Ratcliff (1995) was that priming effect depended on the type of associates on the list. So if, for example, the pair far-near was presented in a list of antonyms there was priming, but if it was presented in a list of synonyms there was no priming effect. These results show that priming effects are flexible and can depend on the context.

\section{GENERAL DISCUSSION}

In two experiments we investigated priming for new associations. Overall performance was better for intact than for recombined word pairs. We obtained priming in lexical decision in Experiment 1 and in perceptual identification in Experiment 2. Thus, we have shown that a priming effect for new associations can be obtained in semantic memory tasks. Furthermore, we have shown that such a priming effect can be obtained even if procedures are used that minimize the use of strategies. Th is is an important finding because, as we have shown in our introduction, priming effects for new association have not always been found. Durgunoglu and Neely (1987) suggested that the effect is obtained under only a limited set of conditions, which indicates that the effect is the result of some type of strategy. Our results, however, suggest that priming for new associations is the result of an automatic process rather than a specific strategy. If priming for new associations is automatic, th is constitutes evidence that these new associations are added to semantic memory.

The priming effect for new associations that we obtained in perceptual identification was rather small. This is a disadvantage of the procedure with masked primes. With such a procedure priming effects for old associations are also quite small because the primes are not consciously perceived and are thus only weakly activated. Therefore, if priming effects are smaller for new associations than for old associations, these effects may not always be observed.

A second issue we investigated was how the relation between prime and target affected the priming effect for new associations. If new associations are added to semantic memory, we should expect to see an interaction that indicates that the effect of study is larger for unrelated than for associated word pairs. Unrelated word pairs do not yet have an association in semantic memory and should therefore benefit more from being learned than associated word pairs that already have a strong association in memory. We sometimes observed this interaction. However, the evidence is not very strong. In Experiment 1 we observed an interaction in the test phase but not in the study phase; in Experiment 2 there was no interaction in the test phase. Schrijnemakers and Raaijmakers (1997) observed an interaction when the procedure was exactly the same as the one we used in Experiment 1, but they did not observe an interaction in other experiments with a slightly different procedure. This suggests that the effect might be the result of a strategy. In general, old associations seem to benefit almost as much as non-associated pairs from being studied. For word pairs that are not associates we did not observe a benefit for words that had a semantic relation over words that were completely unrelated.

This finding suggests that the results observed by Dagenbach et al. (1990) are not the result of differences in semantic relatedness. They found that for new associations that consisted of a new vocabulary word (the prime) and a familiar semantically related word (the target) the priming effect was larger than for new associations that consisted of two 
familiar but semantically unrelated words. However, because they used only a small number of subjects care should be taken with the interpretation of their results.

A third expectation was that the priming effect for new associations should transfer to other semantic memory tasks. Therefore, in the test phase of each experiment we investigated priming for new associations in a task that was not used during the study phase. In Experiment 1 the new associations were studied in lexical decision, and there was priming in lexical decision but not in perceptual identification. In Experiment 2 the new associations were studied in perceptual identification, and there was priming in perceptual identification but not in lexical decision. However, in both experiments there was a small difference between intact and recombined word pairs in the right direction, although this was not reliable. Yet, because all priming effects in our experiments were rather small, we should not conclude that there is no transfer at all. It seems that a more accurate conclusion is that priming for new associations is sensitive to context, and that it will decrease if it is tested in a different task. With more training and a procedure in which priming effects are larger, finding a transfer effect may be more likely.

It has been assumed that semantic memory is an abstraction of specific episodes-in other words, that semantic memory develops out of repeated experiences (Dagenbach et al., 1990). If information in semantic memory is abstract, retrieval should be context independent. If a word is activated, its associates also become activated to some degreee, and this should not depend on the context in which that word is presented. Similarly, information that is strongly related to a specific context should not be integrated into semantic memory. However, our results show that this is not always true. Our finding of automatic priming for new associations in semantic memory tasks indicates that these new associations are integrated in semantic memory. Yet, there was hardly any difference between related and unrelated pairs. Because the related pairs are already in semantic memory and the unrelated are not, we expected the effect of study to be larger for new than for old associations. It seems that for the old associations the amount of learning that is specific for the study context is the same as that for the new associations. The context sensitivity of the priming effect that results from studying is also the same for old and new associations. This is apparent from the lack of transfer effects for all types of intact word pairs. Thus, semantic memory may not consist of abstract information that is retrieved whenever a word is activated, but rather it seems to be more flexible. Storage and retrieval of information from semantic memory is dependent on the context in which a word is encountered. Other studies have also shown that both the present context (McKoon \& Ratcliff, 1995) and recent experiences with words (Dagenbach et al., 1989; Pecher et al., 1998) affect what aspects of a word's meaning are activated at a certain moment.

In our present study the overlap between the study and test tasks determines whether there is priming for new associations. When a word pair is encountered in the context of one test task, processing is facilitated if recent experiences with that pair were in the same context (e.g. in the study phase). If recent experiences with the pair were in the context of a different task, processing is not facilitated. Thus, our results show that, even when new associations are integrated in semantic memory, the existence of priming for them is still dependent on the context. 


\section{REFERENCES}

Anderson, J.R. (1983). A spreading activation theory of memory. Journal of Verbal Learning and Verbal Behavior, 22, 261-295.

Balota, D.A., \& Lorch, R.F. (1986). Depth of automatic spreading activation: Mediated priming effects in pronunciation but not in lexical decision. Journal of Experimental Psychology: Learning, Memory, and Cognition, 12, 336-345.

Carroll, M., \& Kirsner, K. (1982). Context and repetition effects in lexical decision and recognition memory. Journal of Verbal Learning and Verbal Behavior, 21, 55-69.

Collins, A.M., \& Loftus, E.F. (1975). A spreading-activation theory of semantic processing. Psychological Review, 82, 407-428.

Dagenbach, D., Carr, T.H., \& Wilhelmsen, A. (1989). Task-induced strategies and near-threshold priming: Conscious influences on unconscious perception. Journal of Memory and Language, 28, 412-443.

Dagenbach, D., Horst, S., \& Carr, T.H. (1990). Adding new information to semantic memory: How much learning is enough to produce automatic priming? Journal of Experimental Psychology: Learning, Memory, and Cognition, 16, 581-591.

De Groot, A.M.B. (1980). Mondelinge woordassociateinormen: 100 woordassociaties op 460 Nederlandse zelfstandige naamwoorden [Oral word association norms: 100 word associations to 460 Dutch nouns]. Lisse: Swets \& Zeitlinger.

De Groot, A.M.B. (1983). The range of automatic spreading activation in word priming. Journal of Verbal Learning and Verbal Behavior, 22, 417-436.

De Groot, A.M.B., Thomassen, A.J.W.M., \& Hudson, P.T.W. (1986). Primed-lexical decision: The effect of varying the stimulus-onset asynchrony of prime and target. Acta Psychologica, 61, 17-36.

Den Heyer, K. (1986). Manipulating attention-induced priming in a lexical decision task by means of repeated prime-target presentations. Journal of Memory and Language, 25, 19-42.

Durgunoglu, A.Y., \& Neely, J.H. (1987). On obtaining episodic priming in a lexical decision task following paired-associate learning. Journal of Experimental Psychology: Learning, Memory, and Cognition, 13, 206-222.

Evett, L.J., \& Humphreys, G.W. (1981). The use of abstract graphemic information in lexical access. Quarterly Journal of Experimental Psychology, 33A, 325-350.

Fischler, I. (1977). Semantic facilitation without association in a lexical decision task. Memory \& Cognition, 5, 335-339.

Goshen-Gottstein, Y., \& Moscovitch, M. (1995). Repetition priming effects for newly formed associations are perceptually based: Evidence from shallow encoding and format specificity. Journal of Experimental Psychology: Learning, Memory, and Cognition, 21, 1249-1262.

Hudson, P.T.W. (1982). Preliminary category norms for verbal items in 51 categories in Dutch. Internal report/ Vakgroep Psychologische Funktieleer. The Netherlands: Katholieke Universiteit Nijmegen.

Lauteslager, M., Schaap, T., \& Schievels, D. (1986). Schriftelijke woordassociatienormen voor 549 Nederlandse zelfstandige naamwoorden. [Written word association norms for 549 D utch nouns]. Lisse: Swets \& Zeitlinger.

Lund, K., Burgess, C., \& Atchley, R.A. (1995). Semantic and associative priming in high-dimensional semantic space. Proceedings of the Cognitive Science Society (pp. 660-665). Hillsdale, NJ: Lawrence Erlbaum Associates, Inc.

Lupker, S.J. (1984). Semantic priming without association: A second look. Journal of Verbal Learning and Verbal Behavior, 23, 709-733.

Masson, M.E.J. (1995). A distributed memory model of semantic priming. Journal of Experimental Psychology: Learning, Memory, and Cognition, 21, 3-23.

M cKoon, G., \& Ratcliff, R. (1979). Priming in episodic and semantic memory. Journal of Verbal Learning and Verbal Behavior, 18, 463-480.

McKoon, G., \& Ratcliff, R. (1986). Automatic activation of episodic information in a semantic memory task. Journal of Experimental Psychology: Learning, Memory, and Cognition, 12, 108-115.

McKoon, G., \& Ratcliff, R. (1992). Spreading activation versus compound cue accounts of priming: 
Mediated priming revisited. Journal of Experimental Psychology: Learning, Memory, and Cognition, 18, $1155-1172$.

McKoon, G., \& Ratcliff, R. (1995). Conceptual combinations and relational contexts in free association and in priming in lexical decision and naming. Psychonomic Bulletin \& Review, 2, 527-533.

McNamara, T.P. (1992a). Priming and constraints it places on theories of memory and retrieval. Psychological Review, 99, 650-662.

McNamara, T.P. (1992b). Theories of priming: I. Associative distance and lag. Journal of Experimental Psychology: Learning, Memory, and Cognition, 18, 1173-1190.

McNamara, T.P. (1994a). Priming and theories of memory: A reply to Ratcliff and McKoon. Psychological Review, 101, 185-187.

McNamara, T.P. (1994b). Theories of priming: II. Types of primes. Journal of Experimental Psychology: Learning, Memory, and Cognition, 20, 507-520.

McRae, K., \& Boisvert, S. (1998). Automatic semantic similarity priming. Journal of Experimental Psychology: Learning, Memory, and Cognition, 24, 558-572.

McRae, K., De Sa, V.R., \& Seidenberg, M.S. (1997). On the nature and scope of featural representations of word meaning. Journal of Experimental Psychology: General, 126, 99-130.

Meyer, D.E., \& Schvaneveldt, R.W. (1971). Facilitation in recognizing pairs of words: Evidence of a dependence between retrieval operations. Journal of Experimental Psychology, 90, 227-234.

Neely, J.H. (1977). Semantic priming and retrieval from lexical memory: Roles of inhibitionless spreading activation and limited-capacity attention. Journal of Experimental Psychology: General, $106,226-254$.

Neely, J.H. (1991). Semantic priming effects in visual word recognition: A selective review of current findings and theories. In D. Besner \& G.W. Humphreys (Eds.), Basic processes in reading: Visual word recognition. Hillsdale, NJ: Lawrence Erlbaum Associates, Inc.

Pecher, D., Zeelenberg, R., \& Raaijmakers, J.G.W. (1998). Does pizza prime coin? Perceptual priming in lexical decision and pronunciation. Journal of Memory and Language, 38, 401-418.

Posner, M.I., \& Snyder, C.R.R. (1975). Attention and cognitive control. In R.L. Solso (Ed.), Information processing and cognition: The Loyola symposium (pp. 55-85). Hillsdale, NJ: Lawrence Erlbaum Associates, Inc.

Ratcliff, R., \& McKoon, G. (1988). A retrieval theory of priming in memory. Psychological Review, 95, $385-408$.

Ratcliff, R., \& McKoon, G. (1994). Retrieving information from memory: Spreading-activation theories versus compound cue theories. Psychological Review, 101, 177-184.

Ratcliff, R., \& McKoon, G. (1995). Sequential effects in lexical decision: Tests of compound cue retrieval theory. Journal of Experimental Psychology: Learning, Memory, and Cognition, 21, 1380-1388.

Schrijnemakers, J.C.M., \& Raaijmakers, J.G.W. (1997). Adding new word associations to semantic memory: Evidence for two interactive learning components. Acta Psychologica, 96, 103-132.

Seidenberg, M.S., Waters, G.S., Sanders, M., \& Langer, P. (1984). Pre- and postlexical loci of contextual effects on word recogn ition. Memory \& Cognition, 12, 315-328.

Shelton, J.R., \& Martin, R.C. (1992). How semantic is automatic semantic priming? Journal of Experimental Psychology: Learning, Memory, and Cognition, 18, 1191-1210.

Smith, M.C., MacLeod, C.M., Bain, J.D., \& Hoppe, R.B. (1989). Lexical decision as an ind irect test of memory: Repetition priming and list-wide priming as a function of type of encoding. Journal of Experimental Psychology: Learning, Memory, and Cognition, 15, 1109-1118.

Tulving, E. (1972). Episodic and semantic memory. In E. Tulving \& W. Donald son (Eds.), Organization of memory. New York: Academic Press.

Tulving, E. (1983). Elements of episodic memory. New York: Oxford University Press.

Tulving, E. (1984). Precis of elements of episodic memory. The Behavioral and Brain Sciences, 7, 223-268.

Van Loon-Vervoorn, W.A., \& Van Bekkum, I.J. (1991). Woordasociatie lexicon [Word association lexicon]. Amsterdam/ Lisse: Swets \& Zeitlinger.

Williams, J.N. (1996). Is automatic priming semantic? European Journal of Cognitive Psychology, 8, $113-161$. 
Zeelenberg, R., Pecher, D., De Kok, D., \& Raaijmakers, J.G.W. (1998). Inhibition for nonword primes in lexical decision re-examined: The influence of instructions. Journal of Experimental Psychology: Learning, Memory, and Cognition, 24, 1058-1079.

Original manuscript received 20 May 1997 Accepted revision received 1 July 1998 